\title{
Incisional Hernias: Risk Factors and Treatment in a Context of Limited Resources
}

\author{
Souleymane Ouedraogo ${ }^{*}$, Salam Ouedraogo ${ }^{1}$, Jean-Luc Kambire ${ }^{1}$, Mamadou Windsouri ${ }^{1}$, \\ Mamadou T. Traore ${ }^{1}$, Maurice Zida², Si Simon Traore ${ }^{2}$ \\ ${ }^{1}$ Department of Surgery, University Ouaga 1 Pr Joseph Ki Zerbo, Ouagadougou, Burkina Faso \\ ${ }^{2}$ Department of General and Digestive Surgery, University Ouaga 1 Pr Joseph Ki Zerbo, Ouagadougou, Burkina Faso \\ Email: *souleymane.oued@yahoo.fr
}

How to cite this paper: Ouedraogo, S., Ouedraogo, S., Kambire, J.-L., Windsouri, M., Traore, M.T., Zida, M. and Traore, S.S. (2017) Incisional Hernias: Risk Factors and Treatment in a Context of Limited Resources. Surgical Science, 8, 451-456. https://doi.org/10.4236/ss.2017.810050

Received: October 2, 2017

Accepted: October 27, 2017

Published: October 30, 2017

Copyright $\odot 2017$ by authors and Scientific Research Publishing Inc. This work is licensed under the Creative Commons Attribution International License (CC BY 4.0).

http://creativecommons.org/licenses/by/4.0/

\section{c) (i) Open Access}

\begin{abstract}
Background: The purpose of this study was to describe the etiologic factors and therapeutic modalities of incisional hernias in the department of surgery at the regional hospital of Tenkodogo, in Burkina Faso. Methods: It is a cross sectional study covering the period from 2010 to 2012. Sampling was comprehensive, including all the patients operated for incisional hernias during this period. Results: Fifty-four patients were included. Their average age was 22.3 years. There were 35 (64.8\%) males and 19 (35.2\%) female patients. We counted 28 large-size incisional hernias, 14 medium-size incisional hernias and 12 incisional hernias of small size. The average time from the first surgery to the diagnosis of incisional hernias was 8 months. Generalized acute peritonitis (44.4\%) and acute intestinal obstructions (22.2\%) were the main indications of initial surgical interventions. Vertical midline incisions have been involved in 37 cases $(68.5 \%)$. Therapeutically, two surgical techniques have been used: open suture repair and open mesh repair. Forty-two patients $(77.8 \%)$ were treated by open suture repair. Twelve patients (22.2\%) benefited from open mesh repair. Post-operative complications were noted in 2 patients. Nine patients $(16.7 \%)$ presented a recurrence after 12 months. Conclusion: In the rural area of Burkina Faso, incisional hernias occur in young patients. Emergencies with abdominal Infections are the main operative indications. Prostheses are relatively high cost and less accessible. The recidivism rate is high.
\end{abstract}

\section{Keywords}

Incisional Hernia, Abdominal Wall Closure, Surgical Treatment, Burkina Faso 


\section{Introduction}

Incisional hernias constitute one of the most common complications of open abdominal surgery. Their impact varies from $3 \%$ to $20 \%$ depending on studies [1] [2]. They are responsible for significant morbidity [3]. Several risk factors have been identified. The most frequent are wound infections observed after the first surgery, intra-abdominal hyperpression and failing parietal closing techniques [4]. The treatment of incisional hernias is surgical. Two main surgical techniques are used. The open suture repair is the less costly technique, but it seems to be the origin of a high rate of recidivism [4] [5]. The best technique uses synthetic prostheses [6] [7]. These prostheses are relatively high cost and less accessible in rural Africa. In this environment, there is therefore a major interest for prevention. This study is aimed at identifying the risk factors and describing the therapeutic modalities of incisional hernias in a secondary hospital in Burkina Faso, in order to improve strategies of treatment and prevention.

\section{Patients and Methods}

This study is aimed at identifying the risk factors and describing the therapeutic modalities of incisional hernias in a secondary hospital in Burkina Faso.

We retrospectively reviewed the medical records of all the patients who underwent surgery for incisional hernia in the general surgery ward of the regional hospital of Tenkodogo (Burkina Faso) between 1 January 2010 and 31 December 2012. We listed the records of all patients operated for incisional hernia during the study period. However, recurrent incisional hernias, post traumatic hernias and records containing incomplete data were excluded from the study. Patients were monitored for 3 years after incisional hernia surgery. For each patient, we collected the epidemiological, clinical, therapeutic and evolutionary data. We also collected data to classify the incisional hernias in conformity with the "European Hernia Society". This classification distinguishes 3 classes depending on the width of the incisional hernia: small size hernia (less than $5 \mathrm{~cm}$ ), medium size hernia $(5-10 \mathrm{~cm})$ and large size hernia (more than $10 \mathrm{~cm})$.

\section{Results}

A total of 54 patients were included in the study. Their average age was 22.3 years (standard deviation: 11.4 years). We counted 19 female patients $(35.2 \%)$ and 35 male patients (64.8). Sociodemographic and clinical characteristics of the participants are summarized in Table 1.

The average time from the first surgery to the diagnosis of incisional hernias was 8 months (SD 2.6 months). The incisional hernias were classified according to the criteria of the "European Hernia Society". This classification is reported in Figure 1.

According to the first surgery, acute generalized peritonitis was involved in 24 cases (44.4\%). The distribution of patients according to the indication of the first surgery is reported in Table 2. 
Regarding the type of incision of the first surgery, vertical midline incisions were the most providers of incisional hernias with 37 cases (68.5\%). The distribution of patients according to the type of initial incision in the first surgery is reported in Table 3.

Table 1. Sociodemographic and clinical characteristics of patients.

\begin{tabular}{cccc}
\hline Variables & $\begin{array}{c}\text { Males patients } \\
\mathbf{n}=\mathbf{3 5}\end{array}$ & $\begin{array}{c}\text { Females patients } \\
\mathbf{n}=\mathbf{1 9}\end{array}$ & $\begin{array}{c}\text { Total } \\
\mathbf{n}=\mathbf{5 4}\end{array}$ \\
\hline Age & 5 & 3 & 8 \\
$10-19$ years & 14 & 4 & 18 \\
$20-29$ years & 11 & 7 & 18 \\
$30-39$ years & 3 & 1 & 4 \\
$40-49$ years & 1 & 2 & 3 \\
$50-59$ years & 1 & 2 & 3 \\
$60-69$ years & & & 18 \\
Symptoms & 14 & 4 & 36 \\
Symptomatic & 21 & 15 & \\
Asymptomatic & & & 41 \\
Body mass index (BMI) & 27 & 14 & \\
$<25$ & 8 & 5 & \\
$\geq 25$ & & & \\
\hline
\end{tabular}

Table 2. Distribution of patients according to the indication of the first surgery.

\begin{tabular}{ccc}
\hline Indication of the first surgery & Total number & Percentage \\
\hline Acute generalized peritonitis & 24 & 44.4 \\
Acute intestinal obstructions & 12 & 22.2 \\
Abdominal tumors & 03 & 5.6 \\
Hepatobiliary diseases & 6 & 11.1 \\
Cesarean section & 2 & 3.7 \\
Hernias & 2 & 3.7 \\
Others & 5 & 9.3 \\
Total & 54 & 100 \\
\hline
\end{tabular}

Table 3. Distribution of patients according to the type of incision made during the first surgery.

\begin{tabular}{ccc}
\hline Types of incision & Total number & Percentage \\
\hline Vertical midline incision & 37 & 68.5 \\
Transverse sub umbilical incision & 6 & 11.1 \\
Transverse supra umbilical incision & 3 & 5.6 \\
Pfannensteil incision & 2 & 3.7 \\
Others incisions & 6 & 11.1 \\
Total & 54 & 100 \\
\hline
\end{tabular}




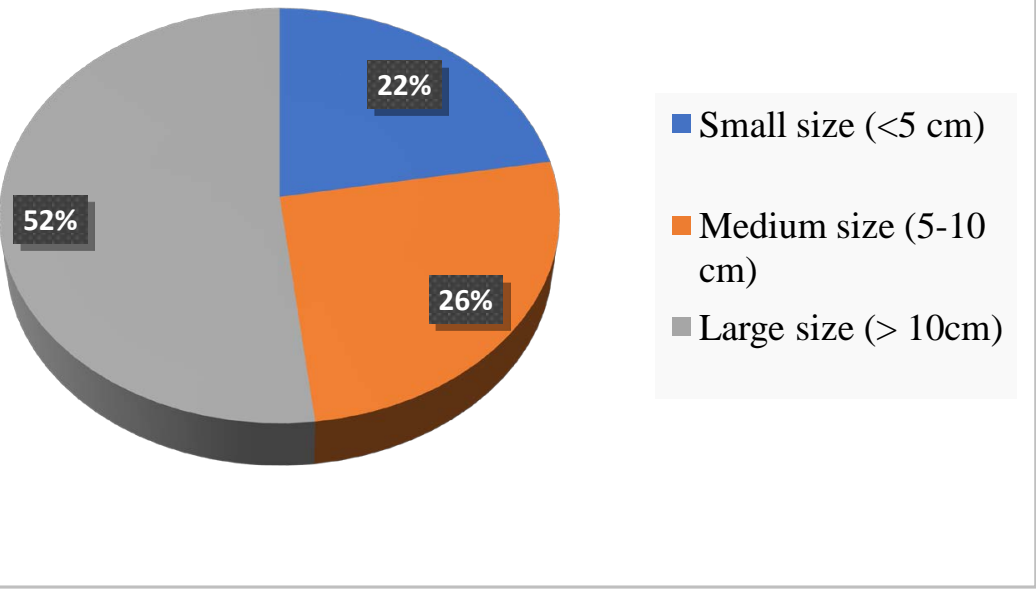

Figure 1. Distribution of the patients according to the size of incisional hernia.

All patients were operated on. The interventions took place under general anaesthetic. Antibiotic prophylaxis based on ceftriaxone was conducted in anesthetic induction. It has been continued for 3 days after surgery. Two surgical techniques have been used: open suture repair and open mesh repair. Open suture repair was proposed to patients who could not pay for a prosthesis. Forty-two patients (77.8\%) were treated by open suture repair. It came with a suture overlap uniting the aponeuroses of wide abdominis or rectus abdominis between them. This suture was made with resorbable thread.

Twelve patients (22.2\%) benefited from open mesh repair. Polypropylene implants have been used. The technique consisted in a dissection of the muscle and fascial plans. The graft was placed in pre-aponeurotic and retro muscular position. The mean length of hospital stay for all patients was 3.4 days $(\mathrm{SD}=1.8)$. In the immediate postoperative, 2 cases of abdominal wall hematoma were noted. Nine patients (16.7\%), all treated by open suture repair, presented recurrence after 12 months. Open mesh repair has been proposed to these patients. No recurrence was observed in patients who received a prosthetic treatment.

\section{Discussion}

Incisional hernias occurred in relatively young patients in our context, the average age of onset was 22.3 years. In Europe, the average age varies from 50 to 60 years [6] [8]. This difference could be explained by the fact that our study was conducted in a general surgery ward carrying out pediatric surgery at the same time. The average time of onset of incisional hernias was 8 months. Incisional hernias usually appear during the first year following the first surgery [9]. It is therefore a relatively early complication. We noticed a predominance of large size incisional hernias at the expense of incisional hernias of small size. In Western literature, there is a predominance of small-size incisional hernias [9]. This difference could be explained by geographic and financial inaccessibility to hos- 
pital structures in our context. This inaccessibility made that small-size incisional hernias, which do not generally cause significant discomfort, are not the subject of consultation.

We found a higher frequency of incisional hernias after surgery for acute generalized peritonitis. The occurrence of incisional hernia is influenced by several factors. Clinically, wound infections and obesity are the most commonly reported factors [9]. Wound infections occur especially at the course of contaminated surgery or dirty surgery. In a tropical environment, acute generalized peritonitis is often due to ileal or gastric perforation [10]. Their treatment constitutes a contaminated surgery, which accounts for the frequency of incisional hernias.

As for the etiology, incisional hernias were more frequent after vertical midline incision. The type of incision, the closing techniques and the equipment used are also etiological factors ofincisional hernias [11] [12]. Vertical midline incisions have a higher risk ofincisional hernia than Pfannenstiel incision [7] [13].

Therapeutically, open suture repair has been the most used technique. This situation is due to the high cost of prostheses, which makes them less accessible in our context. The alternative might be the assessment of safer suture techniques like the one described by Lázaro Da Silva, which would give results comparable to those of the prosthetic treatment [7].

\section{Conclusion}

In rural areas of Burkina Faso, incisional hernias occur in young patients. Peritonitis and occlusions are the main indications of first surgery. The vertical midline incisions are involved in more than half of the cases. Prostheses are less accessible financially. As such, the treatment mainly involves open suture repair with a high rate of recurrence. The technique of Lázaro Da Silva could be an alternative choice.

\section{References}

[1] Elliott, Y.A., Thomas Kallachil, T. and O’Dwyer, P.J. (2014) Patient Awareness and Symptoms from an Incisional Hernia. International Surgery, 99, 241-246. https://doi.org/10.9738/INTSURG-D-14-00039.1

[2] Fortelny, R.H., Baumann, P., Thasler, W.E., Albertsmeier, M., Riedl, S. and Steurer, W. (2015) Effect of Suture Technique on the Occurrence of Incisional Hernia after Elective Midline Abdominal Wall Closure: Study Protocol for a Randomized Controlled Trial. Trials, 16, 52. https://doi.org/10.1186/s13063-015-0572-x

[3] Alaedeen, D.I., Lipman, J., Medalie, D. and Rosen, M.J. (2007) The Single-Staged Approach to the Surgical Management of Abdominal Wall Hernias in Contaminated Fields. Hernia, 11, 41-45. https://doi.org/10.1007/s10029-006-0164-5

[4] Sit, M., İlgün, A.S., Çakır, A., Çatal, O. and Çakmaz, R. (2014) Comparison of Two Surgical Techniques in Large Incisional Hernias. Journal of Clinical and Experimental Investigations, 5, 36-39. https://doi.org/10.5799/ahinjs.01.2014.01.0355

[5] Sauerland, S., Schmedt, C.G., Lein, S., et al. (2005) Primary Incisional Hernia Repair with or without Polypropylene Mesh: A Report on 384 Patients with 5-Year Follow-Up. Langenbeck's Archives of Surgery, 390, 408-412. 
https://doi.org/10.1007/s00423-005-0567-2

[6] Venclauskas, L., Silanskaitè, J., Kanisauskaitè, J. and Kiudelis, M. (2007) Long-Term Results of Incisional Hernia Treatment. Medicina, 43, 855-860.

[7] Muysoms, F.E., Antoniou, S.A., Bury, K., Campanelli, G., Conze, J. and Cuccurullo, D. (2015) European Hernia Society Guidelines on the Closure of Abdominal Wall Incisions. Hernia, 19, 1-24. https://doi.org/10.1007/s10029-014-1342-5

[8] Kawaguchi, M., Ueno, H., Takahashi, Y., Watanabe, T., Kato, H. and Hosokawa, O. (2015) Transitional Mesh Repair for Large Incisional Hernia in the Elderly. International Journal of Surgery Case Reports, 7, 70-74. https://doi.org/10.1007/s10029-014-1342-5

[9] Zafar, H., Zaidi, M., Qadir, I. and Memon, A.A. (2012) Emergency Incisional Hernia Repair: A Difficult Problem Waiting for a Solution. Annals of Surgical Innovation and Research, 6, 1. https://doi.org/10.1186/1750-1164-6-1

[10] Ouangre, E., Zida, M., Ouedraogo, S., Sanou, A., Bonkoungou, G., Sano, D. and Traoré, S.S. (2012) Les activités chirurgicales du bloc opératoire dans un hôpital semi-urbain du Burkina Faso en Afrique subsaharienne: cas du Centre Hospitalier Régional (C.H.R.) de Dédougou. [Surgical Activities in a Semi-Urban Hospital of Burkina Faso in Sub-Saharan Africa: Case of the Regional Hospital Center of Dedougou.] Annals of the University of Ouagadougou, 008, 101-106.

[11] Grantcharov, T.P. and Rosenberg, J. (2001) Vertical Compared with Transverse Incisions in Abdominal Surgery. European Journal of Surgery, 167, 260-267. https://doi.org/10.1080/110241501300091408

[12] Fink, C., Baumann, P., Wente, M.N., Knebel, P., Bruckner, T. and Ulrich, A. (2014) Incisional Hernia Rate 3 Years after Midline Laparotomy. British Journal of Surgery, 101, 51-54. https://doi.org/10.1002/bjs.9364

[13] Diener, M.K., Voss, S., Jensen, K., Buchler, M.W. and Seiler, C.M. (2010) Elective Midline Laparotomy Closure: The Inline Systematic Review and Meta-Analysis. Annals of Surgery, 251, 843-856. https://doi.org/10.1097/SLA.0b013e3181d973e4 